\title{
Failure of aneurysmectomy to improve left ventricular function
}

\author{
MICHAEL SESTO, FRANZ SCHWARZ, KLAUS-ULRICH THIEDEMANN, \\ WILLEM FLAMENG, AND MARTIN SCHLEPPER
}

From the Kerckhoff Klinik, Max Planck Gesellschaft, Bad Nauheim, West Germany

SUMMARY Biplane left ventricular angiography was performed in 22 patients with isolated obstructive disease of the anterior descending branch of the left coronary artery and with an anterior aneurysm following transmural myocardial infarction. Six patients were restudied between 6 and 10 months after aneurysmectomy. Left ventricular reserve was estimated by analysis of a spontaneous postextrasystolic beat. Using angiographic techniques a contractile section, a transitional section, and a noncontractile section were identified. From the surgical patients the excised aneurysm and a transmural needle biopsy of the transitional section were investigated by light microscopy. With increasing volumes of noncontractile and transitional sections, total end-diastolic volume $(r=0.81, P<0.001)$ and endsystolic volume $(r=0.94, P<0.001)$ increased linearly, while the ejection fraction decreased $(r=0.70$, $P<0.001)$. No relation was found between the combined volumes of the noncontractile and transitional sections on the one hand, and the end-diastolic volume, the end-systolic volume, or the ejection fraction of the contractile section on the other hand.

After ancurysmectomy a significant decrease was found in end-diastolic volume (194 to $133 \mathrm{ml} / \mathrm{m}^{2}$, $\mathrm{P}<0.001)$ and end-systolic volume $\left(124\right.$ to $\left.83 \mathrm{ml} / \mathrm{m}^{2}, \mathrm{P}<0.001\right)$ but no change occurred in ejection fraction (35 to $37 \%$ ) and left ventricular end-diastolic pressure (23 to $25 \mathrm{mmHg}$ ). Surgical resection included part of the transitional section, which before surgery had an average ejection fraction of 27 per cent during a normal beat, rising to 41 per cent in a postextrasystolic beat. The transitional section after surgery now formed a large akinetic area of the anterior wall. We conclude that aneurysmectomy in isolated left anterior descending artery disease with anterior aneurysm fails to improve left ventricular function because the effect of reduction of left ventricular volumes is offset by the destruction of contractile behaviour in the transitional section.

Surgical resection of ventricular aneurysm after myocardial infarction has an appreciable mortality and does not always result in dramatic postoperative improvement (Favaloro et al., 1968; Key et al., 1968; Aranda et al., 1977). Several studies have emphasised the importance of the non-damaged myocardium on operative outcome and cardiac function after aneurysmectomy (Kluge et al., 1971; Watson et al., 1975). The role of the border zone of an infarcted area has not been defined as a determinant of remaining function in the area surrounding the noncontractile segment. Furthermore, little information exists about the overloading effect (Crawford et al., 1971) of the aneurysmal chamber on surviving muscle. This study examined left ventricular function of the contractile, transitional,

Received for publication 12 December 1977 and noncontractile sections of aneurysmal ventricles before and after aneurysmectomy by biplane cineangiography. Haemodynamics were then compared with the histology of specimens and biopsy material of the noncontractile and transitional section in surgical cases.

\section{Patients and methods}

We studied 22 patients during diagnostic left heart catheterisation and coronary arteriography who had an anterior aneurysm of the left ventricle following transmural anterior myocardial infarction which had occurred 6 months to 3 years before investigation. Patients with a concomitant postinfarction mitral regurgitation proven by angiography and patients with additional obstructions of the circumflex branch of the left coronary artery or the right 
coronary artery were excluded from the series. All patients had severe obstructive lesions of the anterior descending branch of the left coronary artery. The age of the patients ( 1 woman and 21 men) ranged from 27 to 65 years. Six patients were restudied between 6 and 10 months after aneurysmectomy without aortocoronary bypass surgery. Another 9 patients studied because of chest pain but found to have no evidence of heart disease served as controls. The age of these patients ranged from 28 to 55 years ( 2 women and 7 men).

All patients were studied during routine heart catheterisation for evaluation of coronary heart disease. Propranolol and nitrates were discontinued 48 hours before investigation. Before injection of contrast material, heart rate, left ventricular systolic pressures, and end-diastolic pressures were measured (via femoral artery) using Pigtail $7 \mathrm{~F}$ or $8 \mathrm{~F}$ catheters and a Statham P23Db pressure transducer at mid-chest position. Left ventricular end-diastolic pressure was measured at the peak of the $R$ wave in lead II of the electrocardiogram. In mid-inspiration (right anterior oblique projection) $50 \mathrm{ml}$ of Urografin 76 were injected over a period of 2 to 4 seconds with a power syringe while biplane cineangiograms were exposed at 32 frames/second on $35 \mathrm{~mm}$ film. During this injection the electrocardiogram (lead II) was recorded continuously. Thereafter coronary arteriography was performed using selective injections in the right and left coronary artery system in several right and left anterior oblique views (Judkins, 1968).
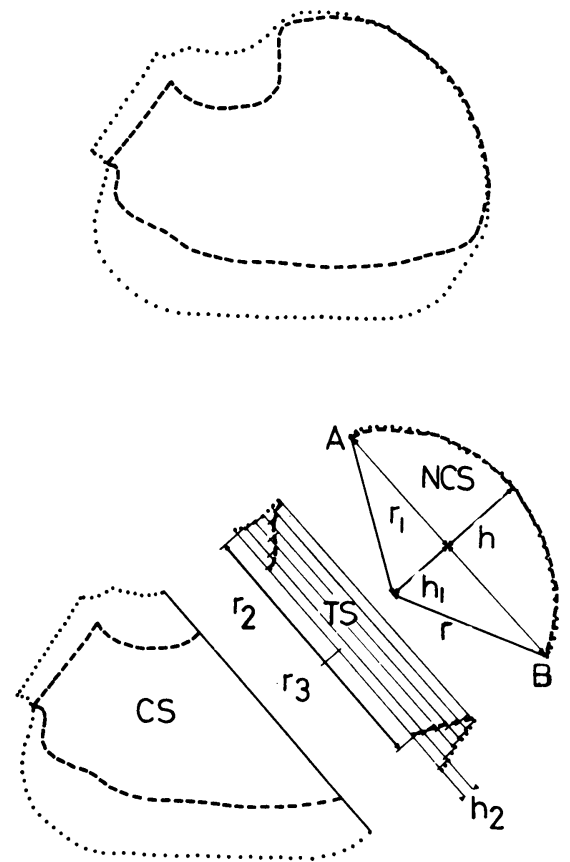

$$
\begin{array}{lr}
\text { NCS }=2 / 3 \pi r^{2} h-1 / 3 \pi r_{1}^{2} h_{1} ; & \text { EFncs }=0 \times 100 \% \\
\text { TSed }=\sum_{1}^{n} \pi r_{2}^{2} h_{2} ; \text { TSes }=\sum_{1}^{n} \pi r_{3}^{2} h_{2} ; \quad \text { EFts } \frac{\text { TSed }- \text { TSes }}{\text { TSed }} \times 100 \%
\end{array}
$$

$$
\text { CSed }=\text { EDV }-(\text { TSed }+ \text { NCS }): \text { CSes }=\text { ESV }-(\text { TSes }+ \text { NCS }) ; \text { EFCS }=\frac{\text { CSed }- \text { CSeS }}{\text { CSed }} \times 100 \%
$$

Fig. 1 The upper panel shows end-diastolic (dotted line) and end-systolic (interrupted line) silhouettes of the frontal plane (right anterior oblique projection) of a ventricle with a large anterior aneurysm. The lower panel shows the technique of dissection into three parts: CS, contractile section; TS, transitional section; NCS, noncontractile section. Formulae for calculation of each section are given: ed, end-diastolic; es, end-systolic; EF, ejection fraction (\%). 


\section{CALCULATIONS}

Quantitative ventriculography was carried out using the area length method for biplane technique (Kasser and Kennedy, 1969). End-diastolic and end-systolic volumes were derived from the largest and smallest silhouettes corrected for magnification and $x$-ray distortion using the apex and the aortic root as reference points. Ventriculographic images selected for analysis were taken from the first 4 sinus beats after injection of contrast material. In addition, in 21 patients with anterior aneurysm and in 7 patients without heart disease a single spontaneous postextrasystolic beat was analysed as proposed by Hamby et al. (1975). In the premature beats the coupling interval, as measured from the electrocardiogram, was less than $400 \mathrm{~ms}$ and was followed by a compensatory pause. In patients with an anterior aneurysm three sections of the left ventricle were determined (Fig. 1): noncontractile section, transitional section, and contractile section. The noncontractile section was the area showing no contraction. The transitional section was defined as a zone showing hypokinesia which was located between the noncontractile and contractile sections.

For demarcation of sections postextrasystolic beats were used. Formulae for calculation of volumes which were derived from Kitamura et al. (1973) are shown in Fig. 1. Total left ventricular volumes were calculated in each instance from biplane cineangiograms, while the noncontractile and transitional sections were calculated using the frontal plane only. Ejection fraction was determined as stroke volume divided by end-diastolic volume times 100 per cent.

\section{SURGERY}

Five patients underwent aneurysmectomy because of congestive heart failure and 1 patient because of severe ventricular rhythm disturbances. Operation was done with the patient on cardiopulmonary bypass, using a disposable bubble oxygenator. Excision of the aneurysm was done as suggested by Favaloro et al. (1968). Direct inspection of the heart showed a demarcation between aneurysm and normal muscle. It was necessary to leave a rim of scar tissue at the edges of the resection for support of the sutures. During operation the excised aneurysm was immediately fixed in 20 per cent formaldehyde. Paraffin sections were stained with haematoxylin-eosin and elastic van Gieson for routine histological examination. In addition, transmural tissues were obtained by needle biopsy (Trucut biopsy needle, Travenol Lab.) from the transitional section and were fixed in buffered 6 per cent glutaraldehyde. Semi-thin sections of these biopsies

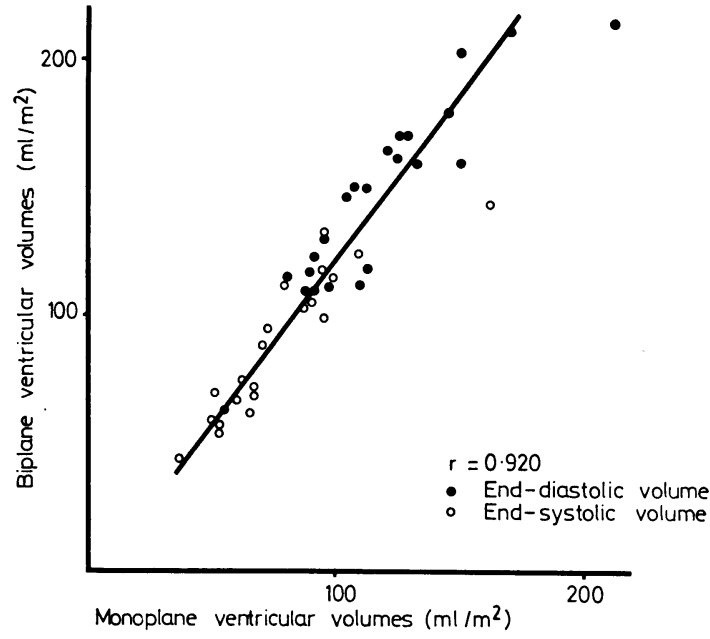

Fig. 2 Relation between monoplane and biplane ventricular volumes for patients with ventricular aneurysms. Monoplane volumes were calculated for the sections of the ventricle as illustrated in Fig. 1 using the ellipsoid of revolution formula for contractile section.

were prepared and stained with alkaline toluidine blue for light microscopy.

\section{Results}

\section{BEFORE SURGERY}

Fig. 2 compares monoplane and biplane ventricular volumes in patients with ventricular aneurysm. The monoplane volumes were calculated for the three sections noncontractile, transitional, and contractile separately. The first two sections were calculated as shown in Fig. 1. The contractile section was then calculated applying the ellipsoid of revolution formula. Summation of these 3 volumes gave the overall monoplane ventricular volumes. The biplane ventricular volumes were calculated from biplane cineangiograms. A good correlation was found using both methods ( $r=0.920)$ which confirms the validity of the techniques used. Individual data of left ventricular pressure, volume, and ejection fraction for all patients with anterior aneurysm are given in the Table. When the volume of the noncontractile section was calculated as a percentage of total left ventricular end-diastolic volume the average was 16 per cent (range 3 to $43 \%$ ). When the volumes of the noncontractile plus transitional sections were calculated as a percentage of total left ventricular end-diastolic volume, the average was 39.5 per cent (range 13 to $65 \%$ ). As shown in the Table, end-diastolic volumes and end-systolic volumes of patients with aneurysms were significantly higher $(P<0.001)$ than those of controls. 
Table Individual data for heart rate (HR), left ventricular systolic pressure (LVSP), end-diastolic pressure (LVEDP), end-diastolic volume (EDVI), ejection fraction $(E F)$ of the noncontractile (NCS), transitional (TS), and contractile (CS) section

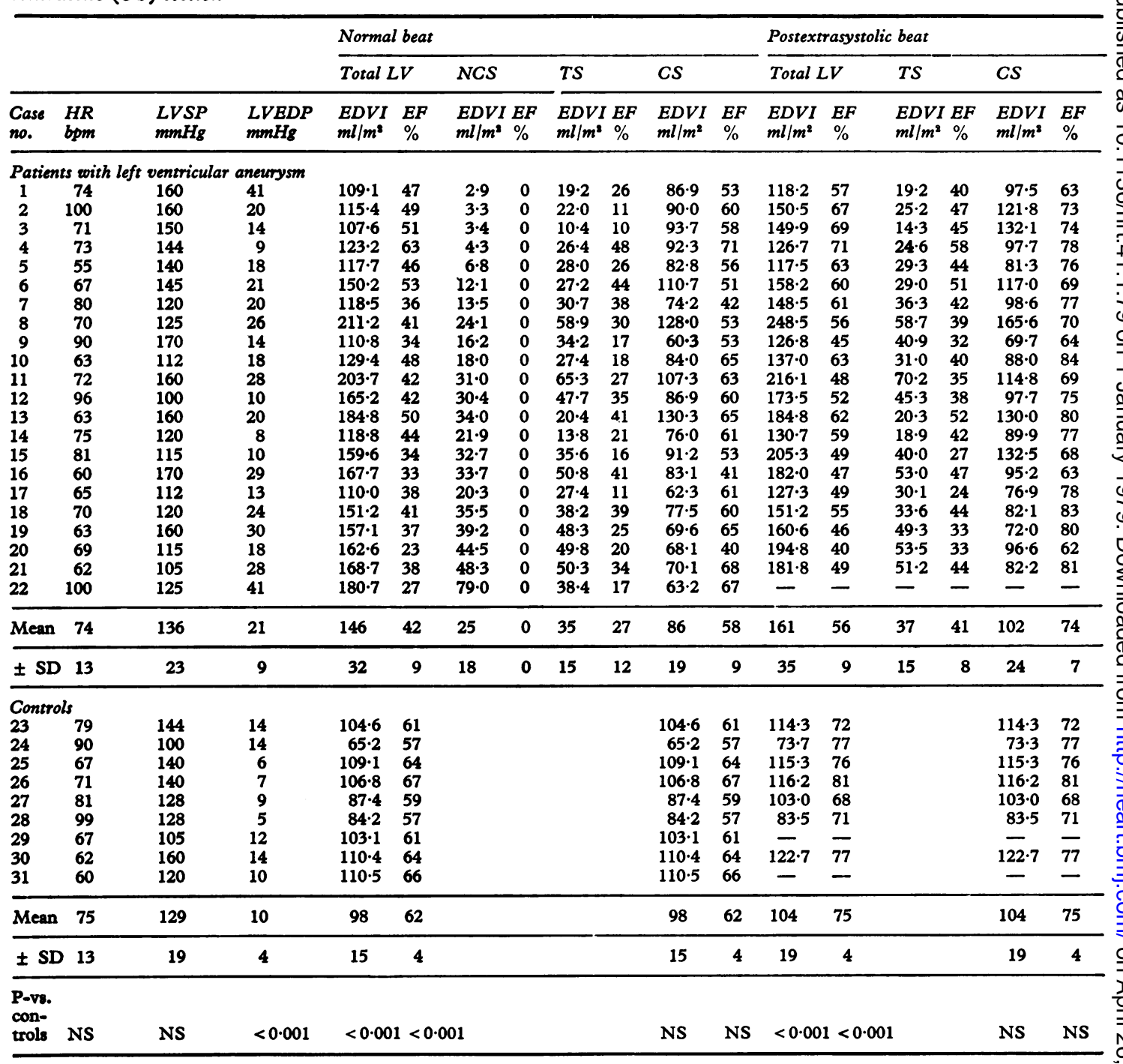

SD, standard deviation; NS, not significant.

Ejection fraction of the total left ventricle was significantly lower in patients with aneurysm (42\%) than in controls $(62 \%, P<0.001)$. The transitional section showed a depressed ejection fraction of 27 per cent which was lower than the ejection fraction of the contractile section $(P<0.001)$ but higher than that of the noncontractile section. The ejection fraction of the transitional section increased after premature beat from 27 to 41 per cent $(P<$ 0.001 , Table). Volumes of the contractile section showed a wide scatter of data but the mean value was not significantly reduced in patients with

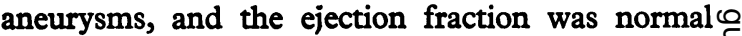
(P $>0.05$, Table). While heart rate and left $\mathbb{D}$ ventricular systolic pressure were comparable in both groups $(\mathbf{P}>0.05$, Table) the left ventricular end-diastolic pressure was significantly raised in patients with aneurysms as compared with controls $\stackrel{?}{\square}$ (21 vs. $10 \mathrm{mmHg}, \mathrm{P}<0.001)$. After the premature $\stackrel{\mathbb{Q}}{\varrho}$ beat, the ejection fraction for the total left ventricle $\bar{x}$ was augmented in both groups but was again 0 significantly lower in patients with aneurysm (56응 


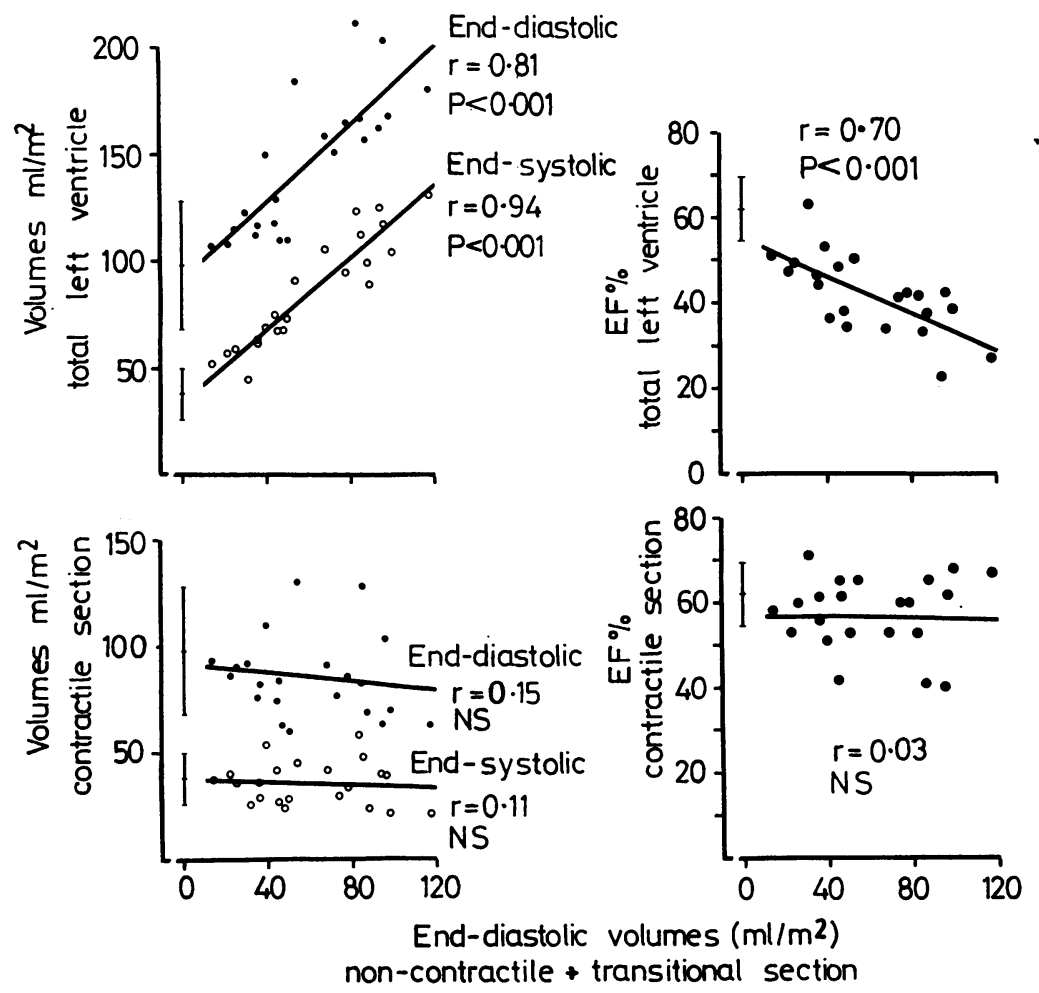

Fig. 3 End-diastolic volumes of noncontractile + transitional section (aneurysmal size) show close relations to end-diastolic volume, end-systolic volume, and ejection fraction (EF) of total left ventricle (upper panels), but not to volumes and ejection fraction of contractile section (lower panels). The contractile section was perfused by normal coronary arteries.

vs. $75 \%, \mathrm{P}<0.001$, Table). The ejection fraction for the contractile section in patients with aneurysms was not different from total ejection fraction in controls ( 74 vs. $75 \%, P>0.05$ ). Fig. 3 represents the relation between end-diastolic volumes of noncontractile plus transitional sections and volumes and ejection fraction of total left ventricle (upper panels). Close relations were found for enddiastolic volume $(r=0.81, P<0.001)$, endsystolic volume $(r=0.94, P<0.001)$, and ejection fraction $(r=0.70, P<0.001)$. The lower panels show no significant relations between end-diastolic volumes of the noncontractile plus transitional sections and end-diastolic volume $(\mathrm{r}=0.15, \mathrm{P}>$ $0.05)$, end-systolic volume $(r=0.11, P>0.05)$, and ejection fraction $(r=0.03, P>0.05)$ of the contractile section.

HISTOLOGICAL DATA

Light microscopy disclosed severe fibrosis mixed with only minimal myocardial tissue in the noncontractile section of the resected aneurysms in all patients studied (Fig. 4). The transitional section, however, contained various amounts of normally arranged myocardium mixed with fibrosis as shown in Fig. 5. The remaining myocardial tissue was found regularly in the subepicardial region, while the fibrosis was confined mainly to the subendocardium. As shown in Fig. 4 and 5, the noncontractile section was considerably thinner than the transitional section (identical magnification in both figures).

\section{BEFORE AND AFTER ANEURYSMECTOMY}

Six patients with large anterior aneurysms underwent aneurysmectomy without coronary bypass surgery. Aneurysmectomy was performed because of congestive heart failure in 5 patients and because of severe ventricular rhythm disturbances in 1 patient. Three of these patients had complete left anterior descending artery occlusion and only poorly visualised collaterals (evaluated according to Levin et al., 1973). Three other patients had a 90 per cent obstruction of the left anterior descend- 


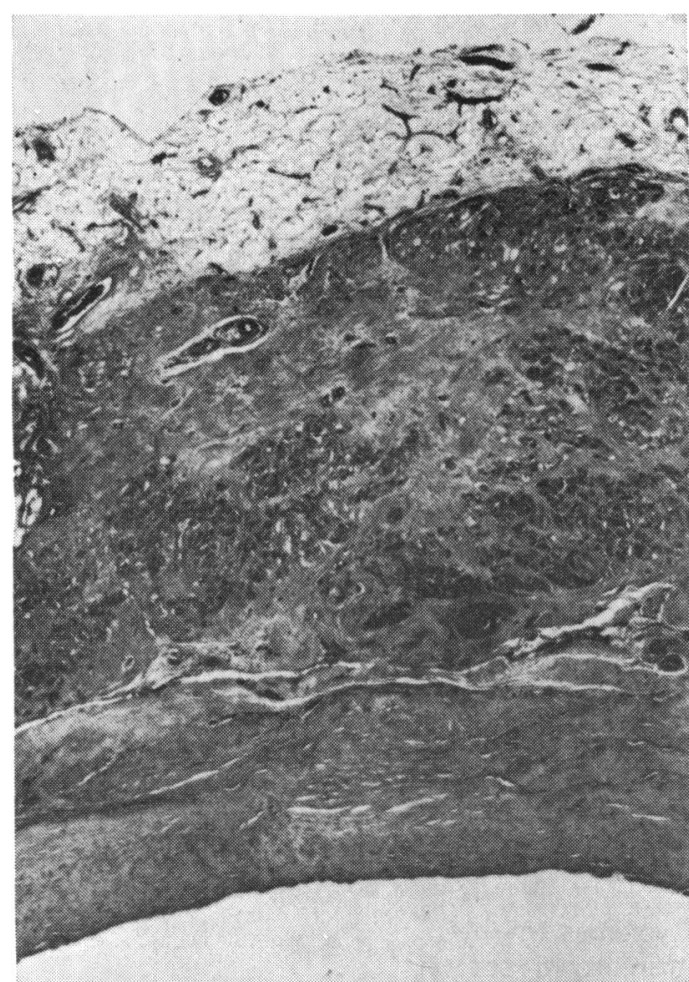

Fig. 4 Light micrograph (cross-section) of the noncontractile section of an anterior aneurysm in a patient with obstructive disease of the anterior descending coronary artery. Severe transmural fibrosis between epicardial fat (upper margin) and endocardium (lower margin) is seen. (Haematoxylin-eosin. $\times 16$.)

ing artery with poor run-off. Poor collaterals were seen in only 1 of these 3 patients. When the volume of the noncontractile section was expressed as a percentage of total left ventricular end-diastolic volume the average in the surgical cases was 24.3 per cent (range 11 to $43 \%$ ), which shows that large aneurysms were found in these patients. Patients were restudied between 6 and 10 months (8.1 \pm 1.8 months) after operation. Heart rate (before $=82$ $\pm 14 \mathrm{bpm}$, after $=79 \pm 10 \mathrm{bpm}$ ) and left ventricular systolic pressure (before $=123 \pm 20 \mathrm{mmHg}$, after $124 \pm 10 \mathrm{mmHg}$ ) were comparable before and after operation. Left ventricular end-diastolic pressure (before $=23 \pm 11 \mathrm{mmHg}$, after $=25 \pm$ $11 \mathrm{mmHg}$ ) remained unchanged after operation. Individual data of volumes, ejection fraction, and end-diastolic pressure are shown in Fig. 6. Enddiastolic volume declined significantly from $194 \pm$ 29 to $133 \pm 30 \mathrm{ml} / \mathrm{m}^{2}(P<0.001)$, and endsystolic volume from $124 \pm 14$ to $83 \pm 17 \mathrm{ml} / \mathrm{m}^{2}$ $(P<0.001)$. End-diastolic and end-systolic volumes

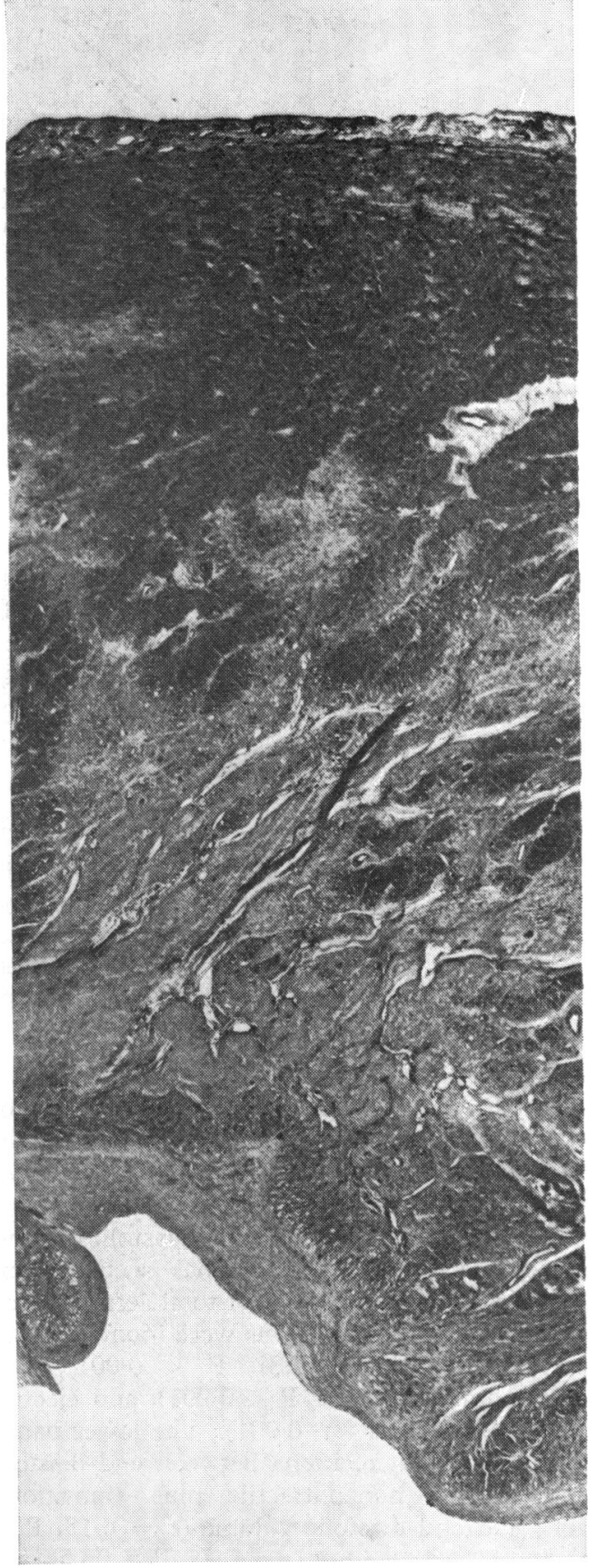

Fig. 5 Light micrograph (cross-section) of the transitional section in the same patient shown in Fig. 4. Note normally arranged myocardium in the subepicardium and fibrosis in the subendocardium. The ventricular wall is thicker in the transitional section than in the noncontractile section of the aneurysm. (Haematoxylineosin. $\times 16$. 


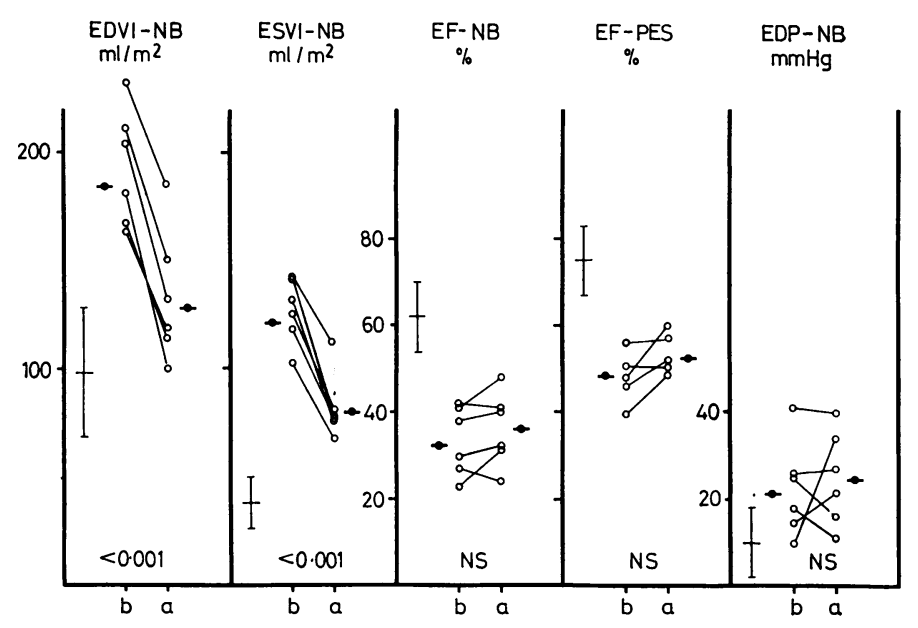

Fig. 6 Haemodynamic data before (b) and after (a) aneurysmectomy. Normal range (mean value \pm 2 standard deviation) is indicated by vertical lines. End-diastolic volumes and end-systolic volumes fell after surgery, but end-systolic volumes did not reach normal level. The ejection fractions $(E F)$ and end-diastolic left ventricular pressure $(E D P)$ remained unchanged. $E D V I-N B=$ end-diastolic volume during normal beat; $E S V I-N B=$ end-systolic volume during normal beat; $E F-P E S$ $=E F$ after postextrasystolic beat; $E D P-N B=$ end-diastolic left ventricular pressure during normal beat.

were raised in patients after aneurysmectomy when compared with controls $(P<0.05)$. The absolute decrease of end-systolic volume index (41 \pm $9 \mathrm{ml} / \mathrm{m}^{2}$ ) was lower than the decrease in enddiastolic volume index $\left(61 \pm 13 \mathrm{ml} / \mathrm{m}^{2}\right)$ when comparing paired data $(P<0.01)$. There was no change in ejection fraction during normal or postextrasystolic beats after operation $(P>0.05)$.

The average end-diastolic volume of the noncontractile section $\left(46 \pm 18 \cdot 2 \mathrm{ml} / \mathrm{m}^{2}\right)$ and transitional section $\left(50.2 \pm 22.5 \mathrm{ml} / \mathrm{m}^{2}\right)$ in operated patients was compared with the volume of the aneurysm resected which was $64.2 \pm 13.8 \mathrm{ml} / \mathrm{m}^{2}$ (calculated as total preoperative end-diastolic volume minus total postoperative end-diastolic volume). Thus, the volume of the aneurysm resected exceeded the volume of the noncontractile section and excision must therefore have included part of the transitional section.

End-diastolic and end-systolic silhouettes of one patient's ventricle before and 6 months after operation are shown in Fig. 7. Before operation a large anterior aneurysm was present; after operation the end-diastolic silhouette was smaller but a large akinetic anterior segment was still found. This figure also depicts a system of 10 hemiaxes, which was used to calculate regional wall motion. Fig. 8 illustrates the percentage shortening of 10 hemiaxes for all patients before (upper panel) and after opera- tion (middle panel) as compared with controls (lower panel) during normal and postextrasystolic beats. It is evident that before and after operation identical hemiaxes are akinetic $\left(\mathbf{R}_{2}-\mathbf{R}_{5}\right)$ while the inferior area perfused by normal coronary arteries shows normal regional wall motion. The hemiaxes $\mathbf{R}_{6}$ and $\mathbf{R}_{7}$ showed a significant increase in wall motion during normal beats after operation $(P<$ 0.05 comparing paired data). After a premature beat no significant increase in regional wall motion was found $(P>0.05)$.

\section{Discussion}

Our series of patients with anterior aneurysm is not a consecutive series because patients with obstructive coronary lesions of the right coronary artery and the circumflex branch of the left coronary artery were excluded. Our patients therefore did not present with two coexisting problems, that is the mechanical disadvantage from the aneurysm and the functional impairment of the contractile section caused by additional coronary obstructions. Our technique for calculating the size of the aneurysm was derived from Kitamura et al. (1973). We modified their technique since we calculated total left ventricular volumes from biplane instead of monoplane cineangiograms. Validity of this technique is given by comparison of monoplane and 


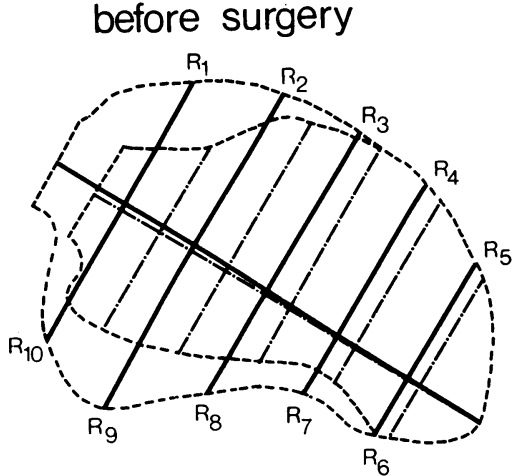

after surgery

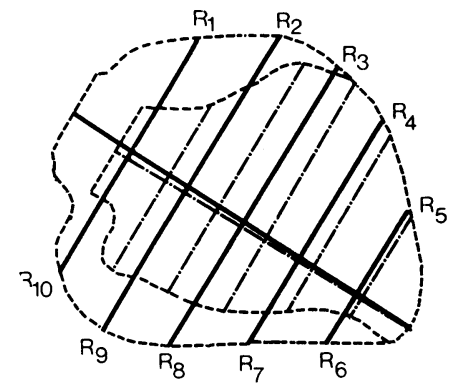

Fig. 7 End-diastolic and end-systolic silhouettes of a ventricle before and after aneurysmectomy. After surgery the ventricular chamber is smaller but a large akinetic area persists. $R_{1}-R_{10}$ are hemiaxes which are drawn to measure regional wall motion.

biplane volumes as shown in Fig. 2. In addition, a border zone (transitional section) was defined as a section with severely depressed but not absent motion. We defined this section in the postextrasystolic beat, since it is well known that inotropic stimulation enhances motion in areas partially fibrotic (Dyke et al., 1974). Our decision seems justified from the histological studies: while the noncontractile section in all patients consisted of fibrosis without myocardium, the transitional section contained considerable amounts of viable myocardium mixed with scar tissue, which explains the transitional section ejection fraction of 27 per cent and the increase after premature beat to 41 per cent. The transitional section most probably represents the border-zone between fibrotic tissue and an area which was ischaemic during acute coronary artery occlusion, but was partially preserved by the development of collaterals (Snow et al., 1955; Schaper, 1971). This hypothesis is further supported by the fact that in 4 of 6 operated patients collaterals were visible before operation. The evolution and distribution of collateral flow during acute myocardial infarction was measured in dogs by the
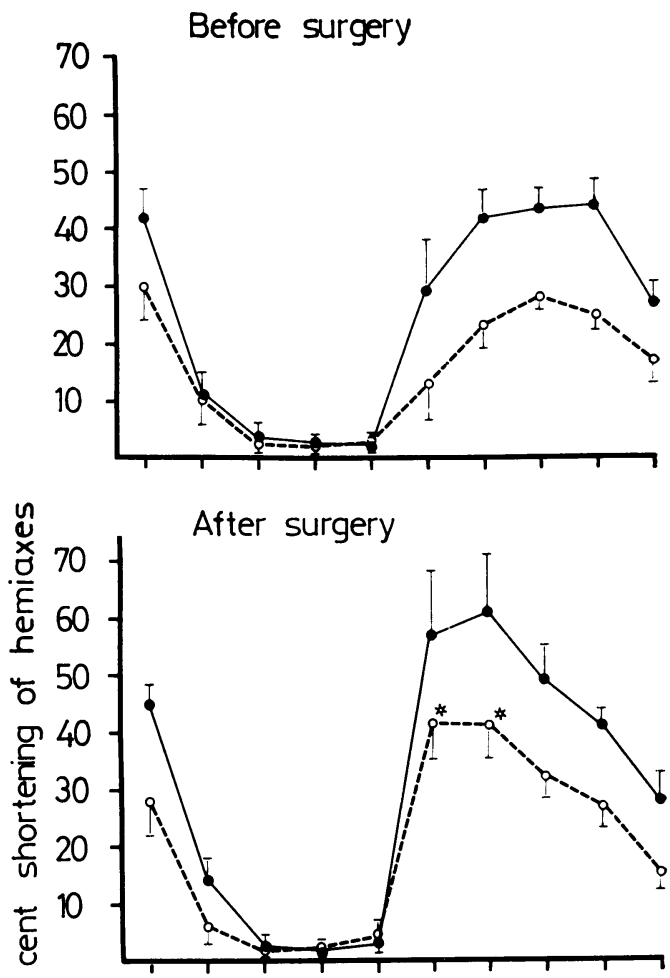

¿ั่

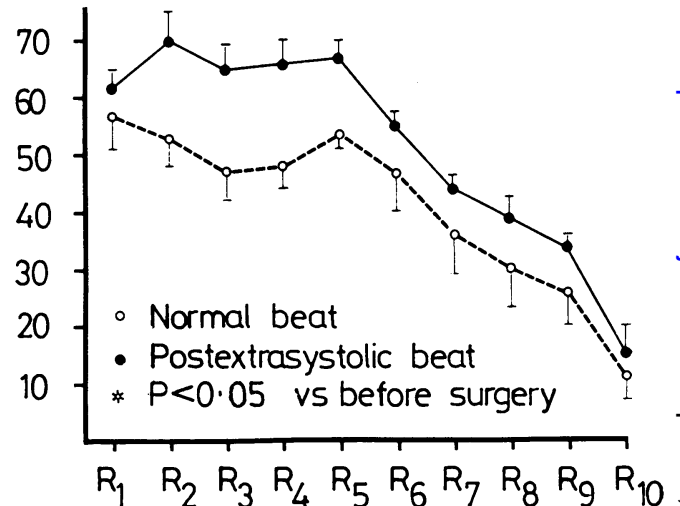

Number of hemiaxes

Fig. 8 Percentage shortening of hemiaxes is shown for anterior aneurysms before and after aneurysmectomy as compared with controls. A lack of motion is seen before and after surgery for $R_{2}-R_{5}$, hypokinesia for $R_{1} . A$ significantly improved wall motion of $R_{6}$ and $R_{7}$ after surgery is evident during normal beats but not during postextrasystolic beats. Interrupted line and open circles $=$ normal beat; uninterrupted line and closed circles = postextrasystolic beat.

tracer microsphere technique and normalisation of flow in ischaemic marginal areas and the sub-o 
epicardium of central areas was found after 24 to 48 hours (Cox et al., 1975; Pasyk and Schaper, 1975).

When the aneurysmal volume was defined as noncontractile plus transitional section, then the contractile section showed a normal contractile behaviour which did not deteriorate with increasing size of aneurysm. Watson et al. (1975) described a wide range of contractile section ejection fractions in ventricular aneurysms; however, in their study 14 of 17 patients had severe obstructive lesions of more than one coronary artery. Our findings are only applicable to a normally perfused contractile section. The relation between size of aneurysm and total ejection fraction (Fig. 3) signifies declining function with increasing aneurysmal size. This relation confirms the results described by Feild et al. (1972) and Kitamura et al. (1973). The normal function and reserve in the contractile section of our patients signifies that the increased systolic load produced by an increased ventricular volume plays no significant role for systolic function of the non-infarcted normal myocardium in patients with aneurysm. From the theoretical point of view, aneurysmectomy should reduce end-diastolic and end-systolic volumes by about the same amount, and the ejection fraction should increase. We have studied 6 patients with anterior aneurysm and isolated disease of the left anterior descending branch of left coronary artery. The decrease of end-systolic volume was found to be significantly less than that of enddiastolic volume, and the ejection fraction remained unchanged. The lack of improvement was further reflected by an unchanged left ventricular enddiastolic pressure. This fact could be the result of insufficient resection of the aneurysm. However, the aneurysms were resected to the transitional section according to the technique of Favaloro et al. (1968) leaving a rim of scar tissue for support of the sutures. On the other hand, the sutures in the transitional section may destroy its contractile behaviour. This latter mechanism is suggested by the wall motion pattern shown in Fig. 7 and 8: a large akinetic area after operation persisted. Studies comparing ventricular function by cineangiography before and after aneurysmectomy are rare. Kitamura et al. (1972) reported a series of 9 patients who underwent aneurysmectomy associated with aortocoronary bypass surgery in 4 patients and internal mammary implants in the remaining 5 patients. The ejection fraction in their series improved from 31 to 44 per cent but remained severely depressed after surgery. In an experimental study in dogs, Pairolero et al. (1970) found no improvement in left ventricular function after excision of a large chronic infarct as measured by the percentage shortening of the angiographic ventricular silhouette and by construction of ventricular function curves. Our study suggests that aneurysmectomy does not significantly improve cardiac function and cardiac reserve, probably because the reduction in end-diastolic and endsystolic volume is partially jeopardised by the fact that transitional section becomes akinetic after the surgical procedure. Further investigation is needed to clarify if a more limited resection (removing the thinned scar only) associated with aortocoronary bypass surgery (revascularising the transitional section) may improve ventricular function in patients with ventricular aneurysm.

\section{References}

Aranda, J. M., Befeler, B., Thurer, R., Vargas, A., El-Sherif, N., and Lazzara, R. (1977). Long-term clinical and hemodynamic studies after ventricular aneurysmectomy and aortocoronary bypass. Fournal of Thoracic and Cardiovascular Surgery, 73, 772-779.

Cox, H. L., Pass, H. I., Wechsler, A. S., Oldham, H. N., Jr., and Sabiston, D. C., Jr. (1975). Coronary collateral blood flow in acute myocardial infarction. Fournal of Thoracic and Cardiovascular Surgery, 69, 117-125.

Crawford, D. W., Barndt, R., Jr., Harrison, E. C., and Lau, F. Y. K. (1971). A model for estimating some of the effects cf aneurysm resection following infarction: preliminary clinical confirmation. Chest, 59, 517-523.

Dyke, S. H., Cohn, P. F., Gorlin, R., and Sonnenblick, E. H. (1974). Detection of residual myocardial function in coronary artery disease using post-extrasystolic potentiation. Circulation, 50, 694-699.

Favaloro, R. G., Effler, D. B., Groves, L. K., Westcott, R. N., Suarez, E., and Lozada, J. (1968). Ventricular aneurysmclinical experience. Annals of Thoracic Surgery, 6, 227-245.

Feild, B. J., Russell, R. O., Jr., Dowling, J. T., and Rackley, C. E. (1972). Regional left ventricular performance in the year following myocardial infarction. Circulation, 46, 679-689.

Hamby, R. I., Aintablian, A., Wisoff, G., and Hartstein, M. L. (1975). Response of the left ventricle in coronary artery disease to postextrasystolic potentiation. Circulation, $51,428-435$.

Judkins, M. P. (1968). Percutaneus transfemoral selective coronary arteriography. Radiologic Clinics of North America, 6, 467-492.

Kasser, I. S., and Kennedy, J. W. (1969). Measurement of left ventricular volumes in man by single-plane cineangiocardiography. Investigative Radiology, 4, 83-90.

Key, J. A., Aldridge, H. E., and MacGregor, D. C. (1968). The selection of patients for resection of left ventricular aneurysm. Fournal of Thoracic and Cardiovascular Surgery, 56, 477-483.

Kitamura, S., Echevarria, M., Kay, J. H., Krohn, B. G., Redington, J. V., Mendez, A., Zubiate, P., and Dunne, E. F. (1972). Left ventricular performance before and after removal of the noncontractile area of the left ventricle and revascularization of the myocardium. Circulation, 45, 1005-1017.

Kitamura, S., Kay, J., Krohn, B. G., Magidson, O., and Dunne, E. F. (1973). Geometric and functional abnormalities of the left ventricle with a chronic localized noncontractile area. American fournal of Cardiology, 31, 701-707. 
Kluge, T. H., Ullal, S. R., Hill, J. D., Kerth, W. J., and Gerbode, F. (1971). Dyskinesia and aneurysm of the left ventricle. Surgical experience in 36 patients. Fournal of Cardiovascular Surgery, 12, 273-280.

Levin, D. C., Sos, T. A., Lee, J. G., and Baltaxe, H. A. (1973). Coronary collateral circulation and distal coronary runoff: the key factors in preserving myocardial contractility in patients with coronary disease. American fournal of Roentgenology, Radium Therapy, and Nuclear Medicine, 119, 474-483.

Pairolero, P. C., McCallister, B. D., Hallermann, F. J., Titus, I. L., and Ellis, F. H., Jr. (1970). Experimental left ventricular akinesis; results of excision. Fournal of Thoracic and Cardiovascular Surgery, 60, 683-693.

Pasyk, S., and Schaper, W. (1975). Myocardial flow and its distribution during acute myocardial infarction in the unanesthetized dog. Verhandlungen der Deutschen Gesell- schaft für Kreislaufforschung, 41, 185-189.

Schaper, W. (1971). The Collateral Circvlation of the Heart. North Holland, Amsterdam; American Elsevier Publishing Company, New York.

Snow, P. J. D., Jones, A. M., and Daber, K. S. (1955). Coronary disease: a pathological study. British Heart fournal, 17, 503-510.

Watson, L. E., Dickhans, D. W., and Martin, R. H. (1975). 을 Left ventricular aneurysm. Preoperative hemodynamics, chamber volume, and results of aneurysmectomy. Circulation, 52, 868-873.

Requests for reprints to Dr Martin Schlepper, 6350 Bad Nauheim, Kerckhoff Klinik, Benekestr. 6-8, West Germany. 